\title{
Sculpting the Bicyclo[3.1.0]hexane Template of Carbocyclic Nucleosides to Improve Recognition by Herpes Thymidine Kinase
}

Maria J. Comin, Riad Agbaria, Tsipi Ben-Kasus, Mahmoud Hulaihel, Chenzhong Liao, Guangyu Sun, Marc C. Nicklaus, Jeffrey R. Deschamps, Damon A. Parrish and Victor E. Marquez*

${ }^{1}$ H AND ${ }^{13}$ C NMR SPECTRA OF NEW COMPOUNDS 

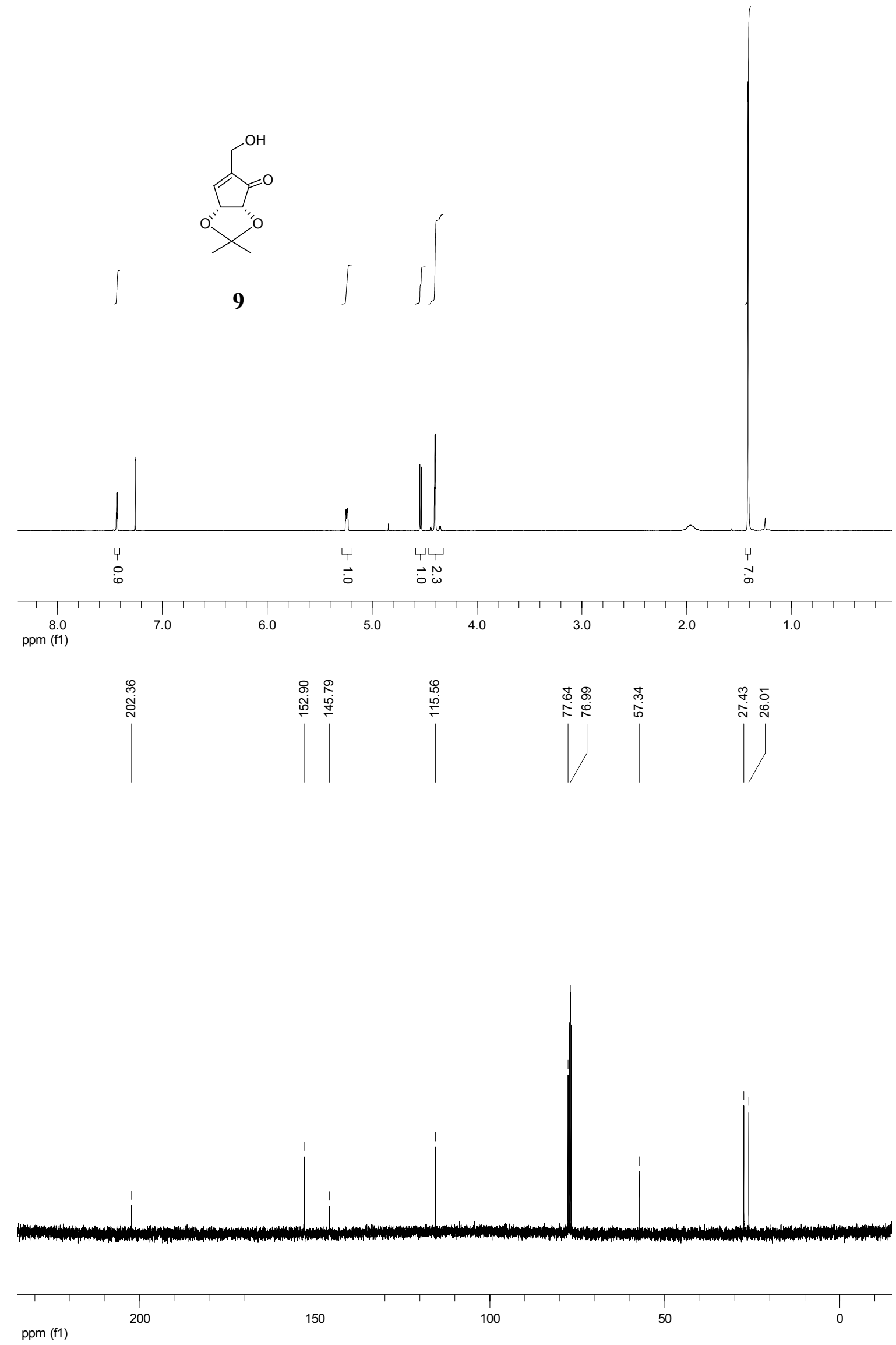

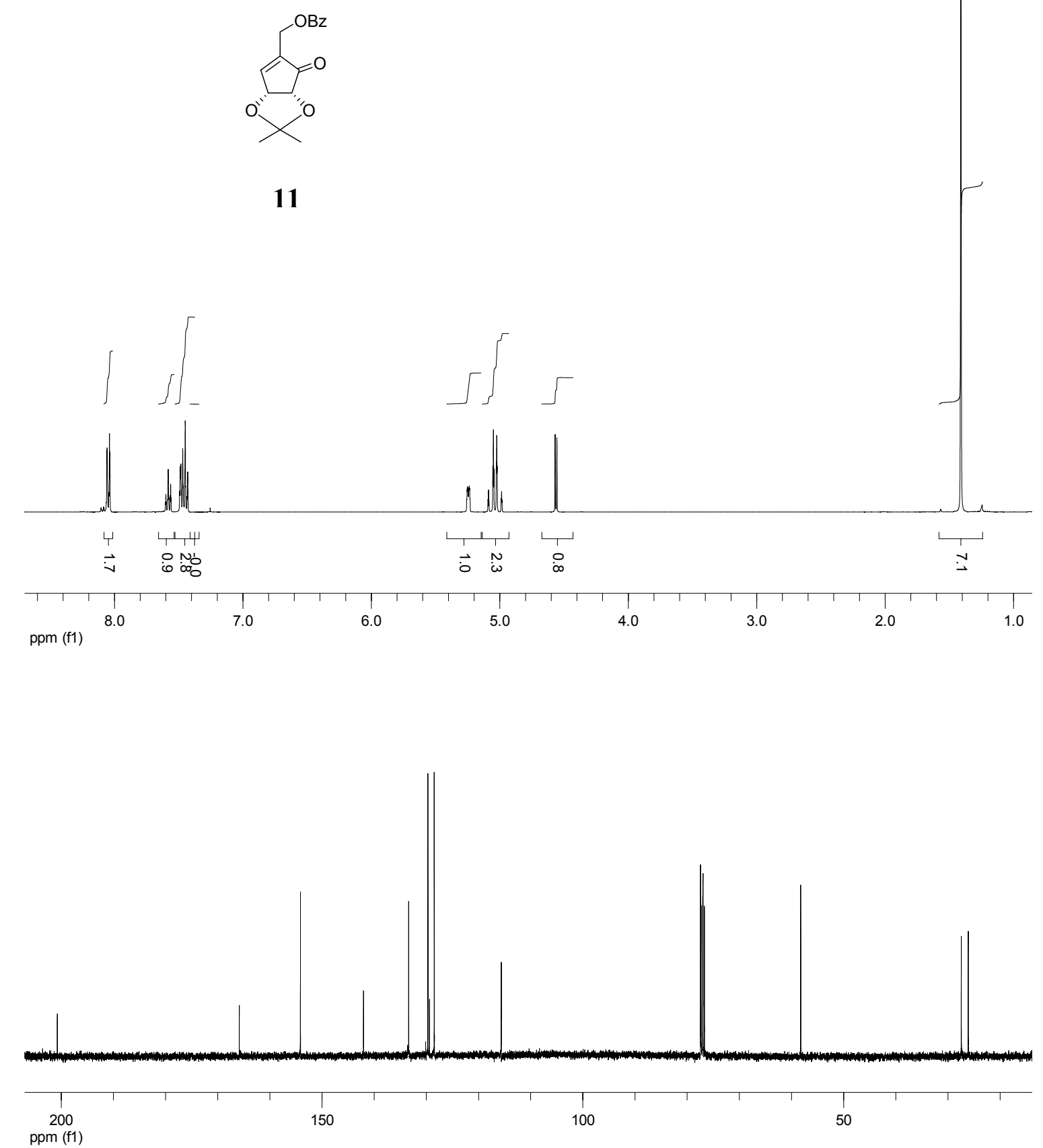

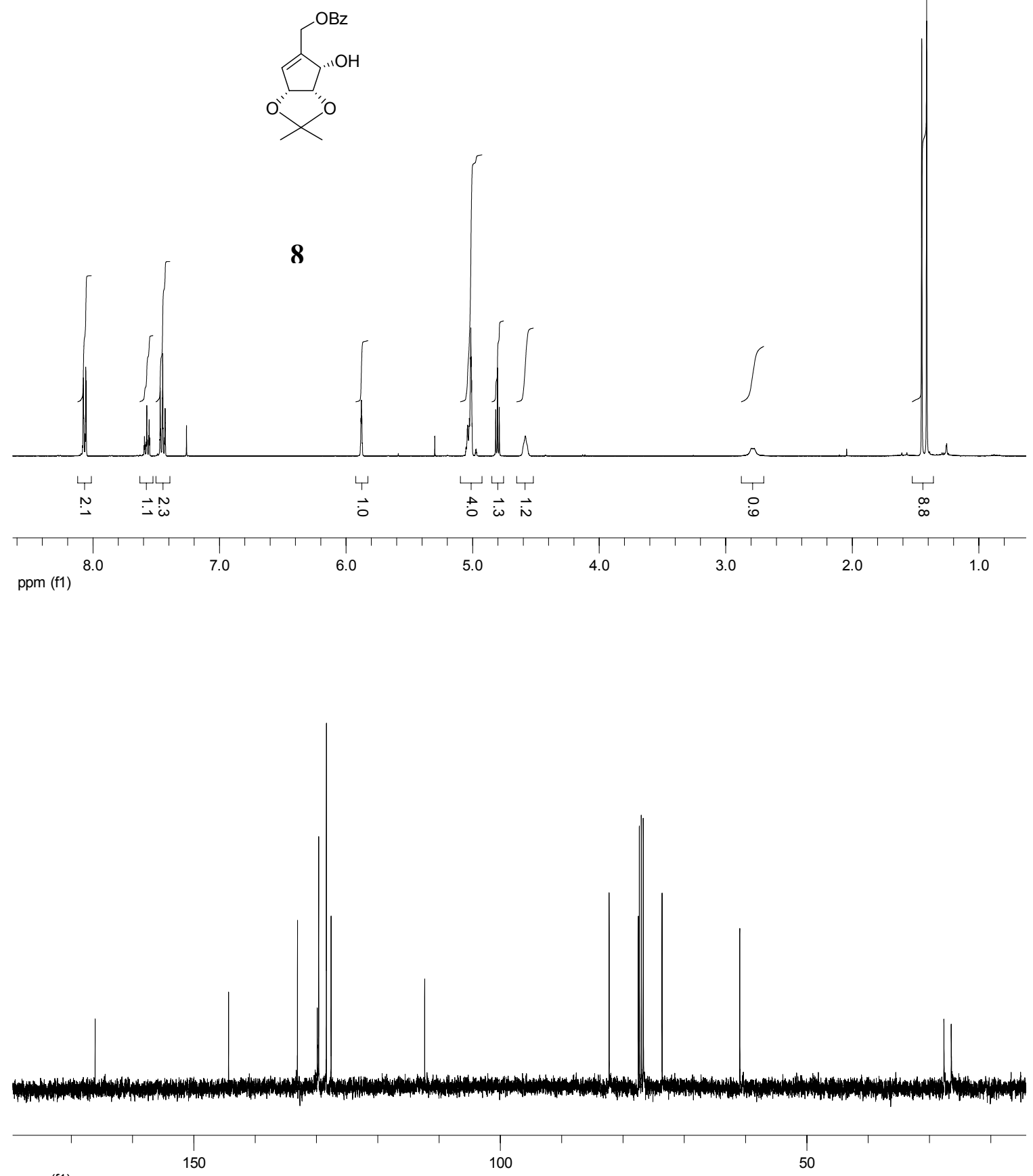

ppm (f1) 

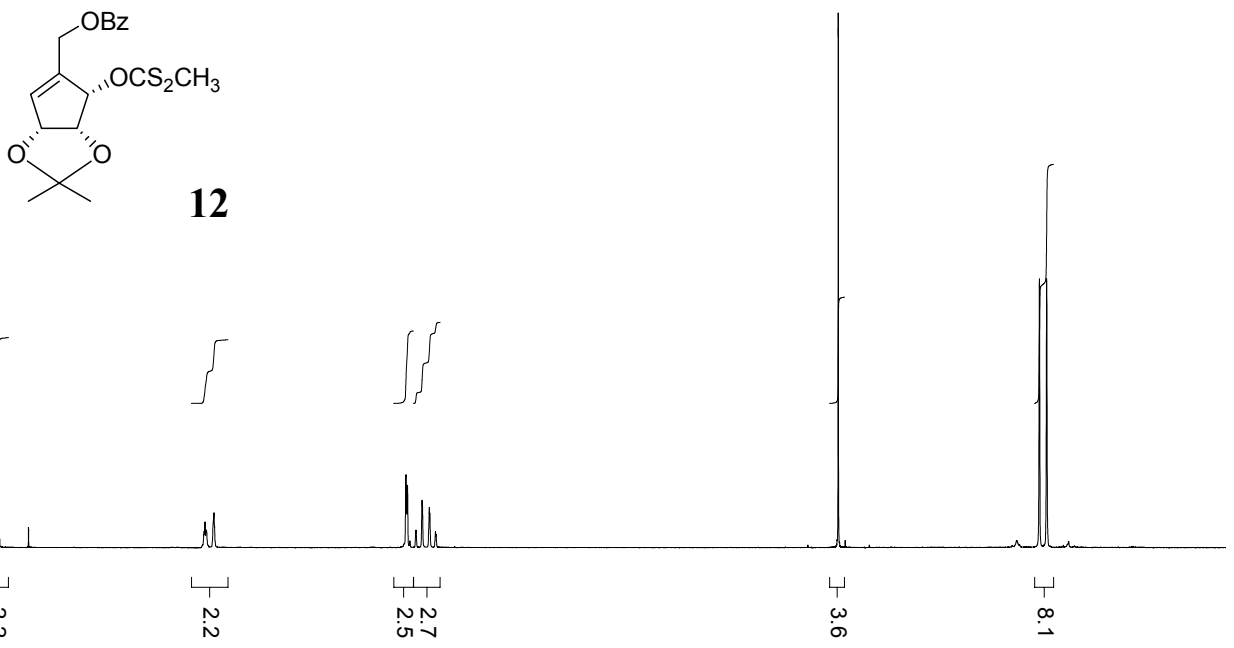

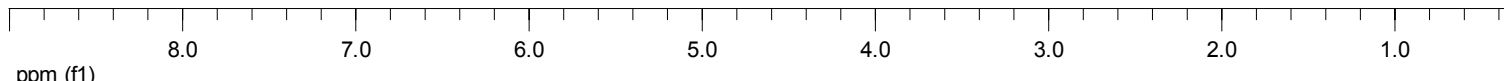

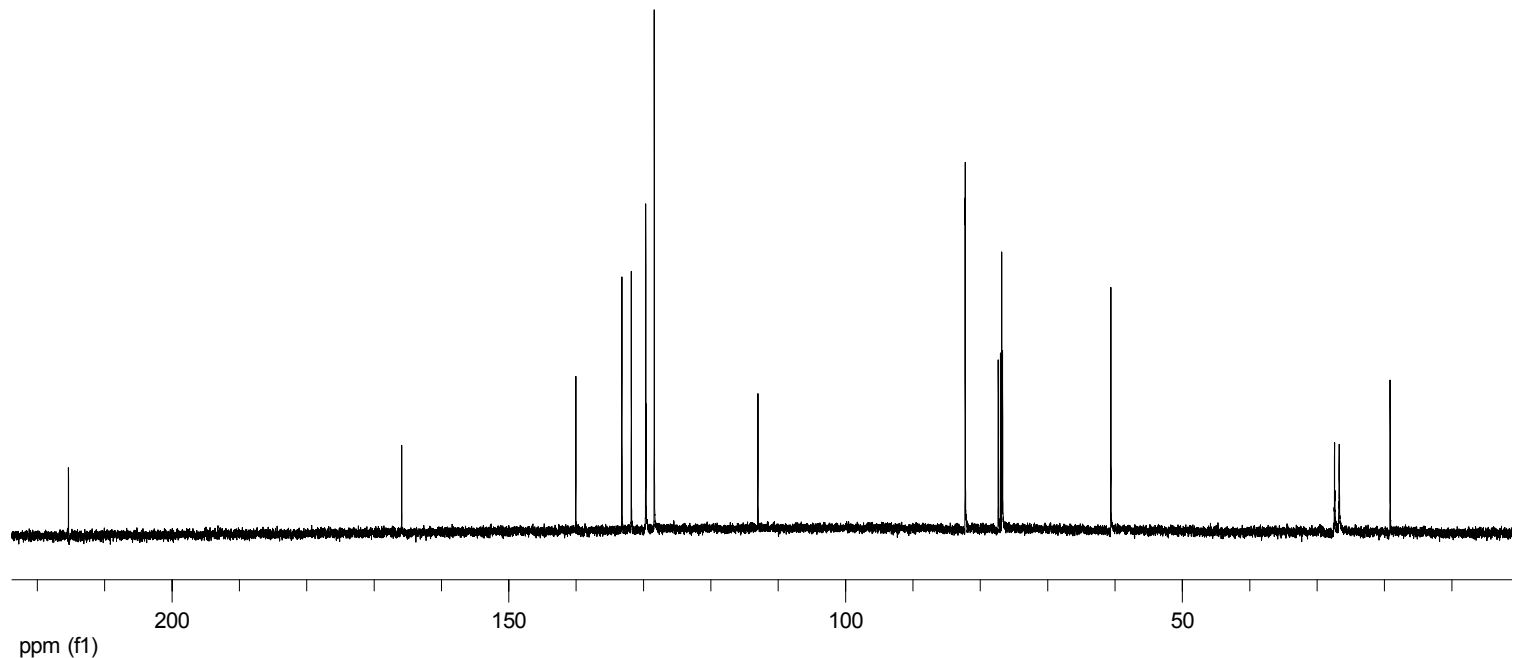



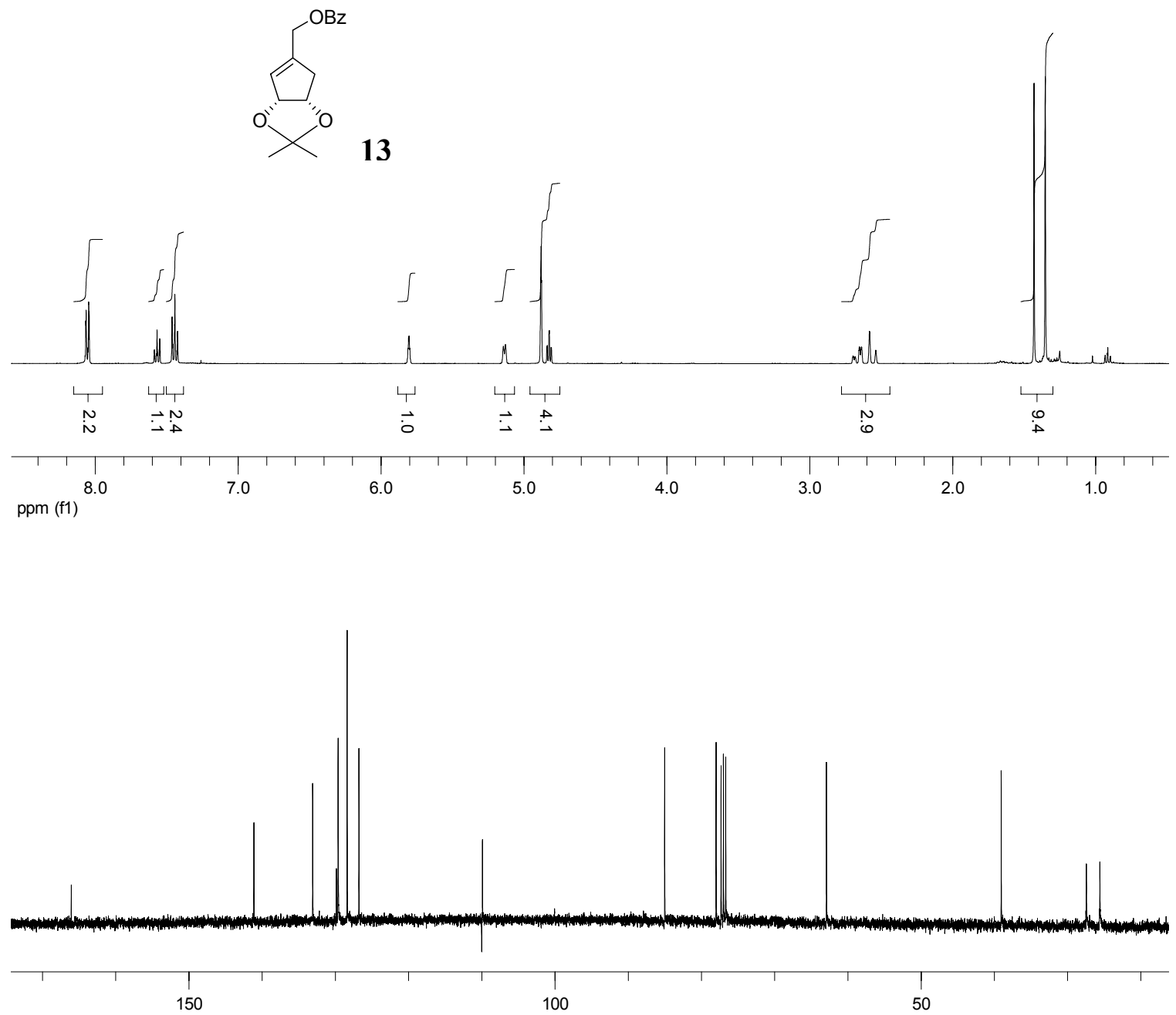

ppm (f1) 

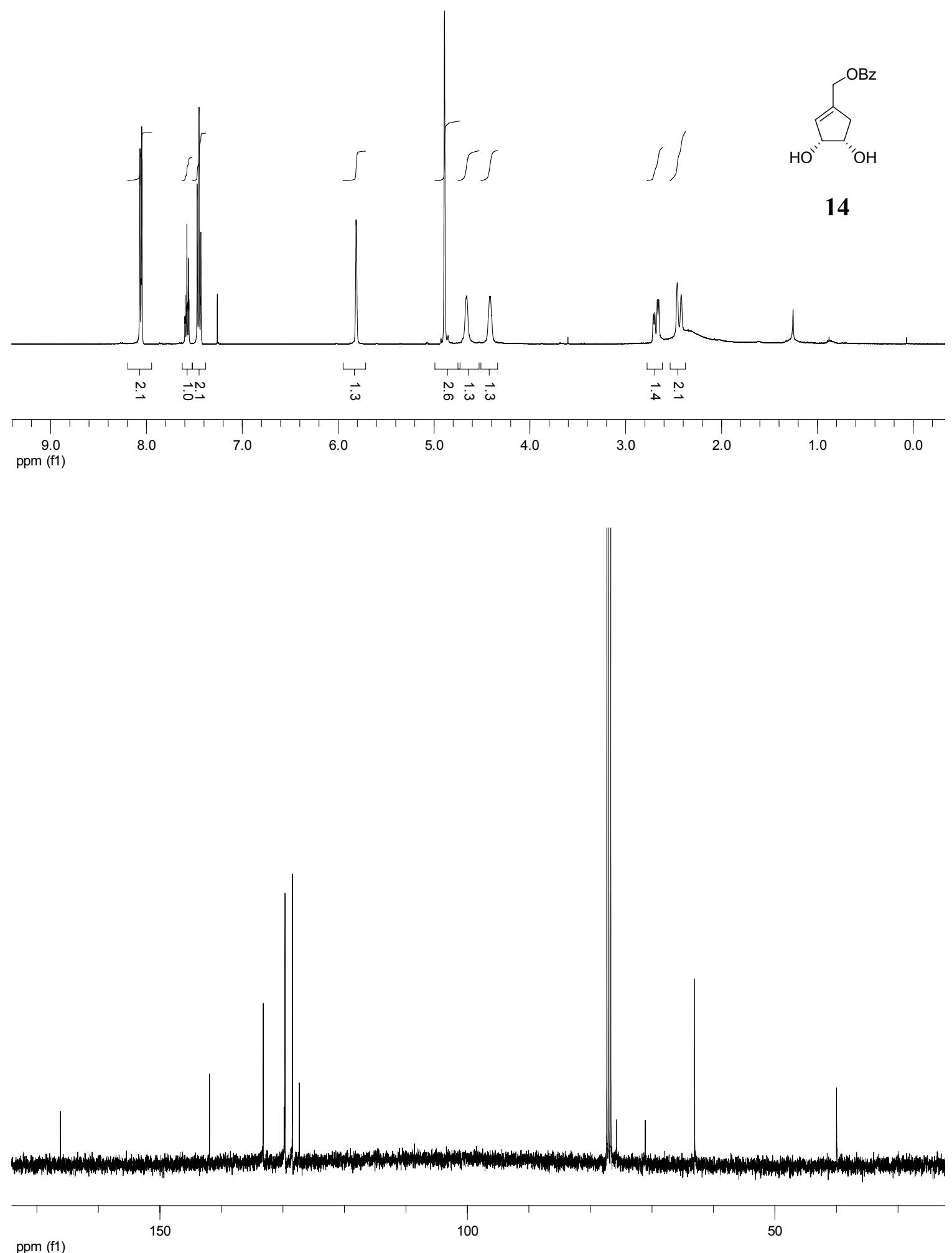

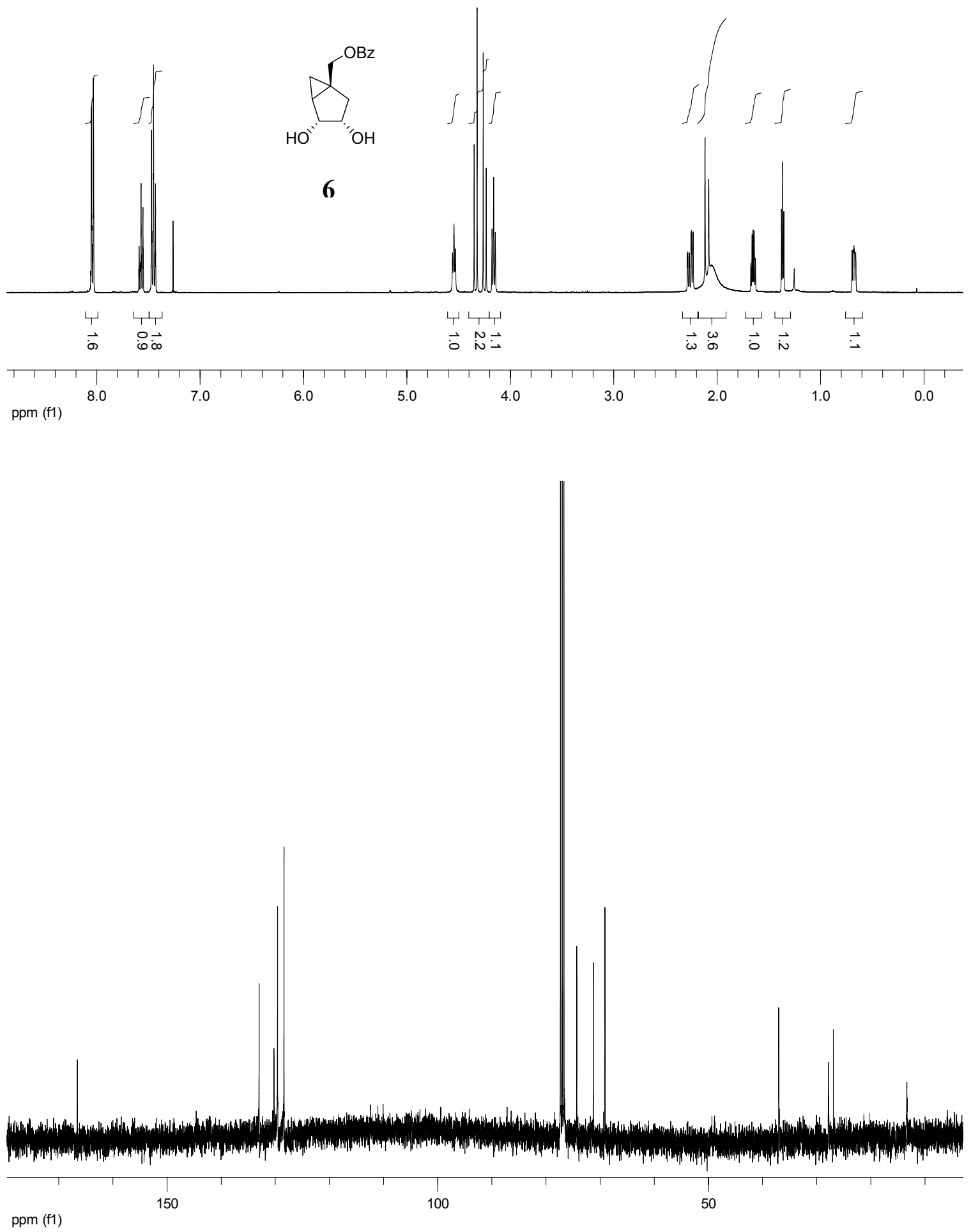

S8 


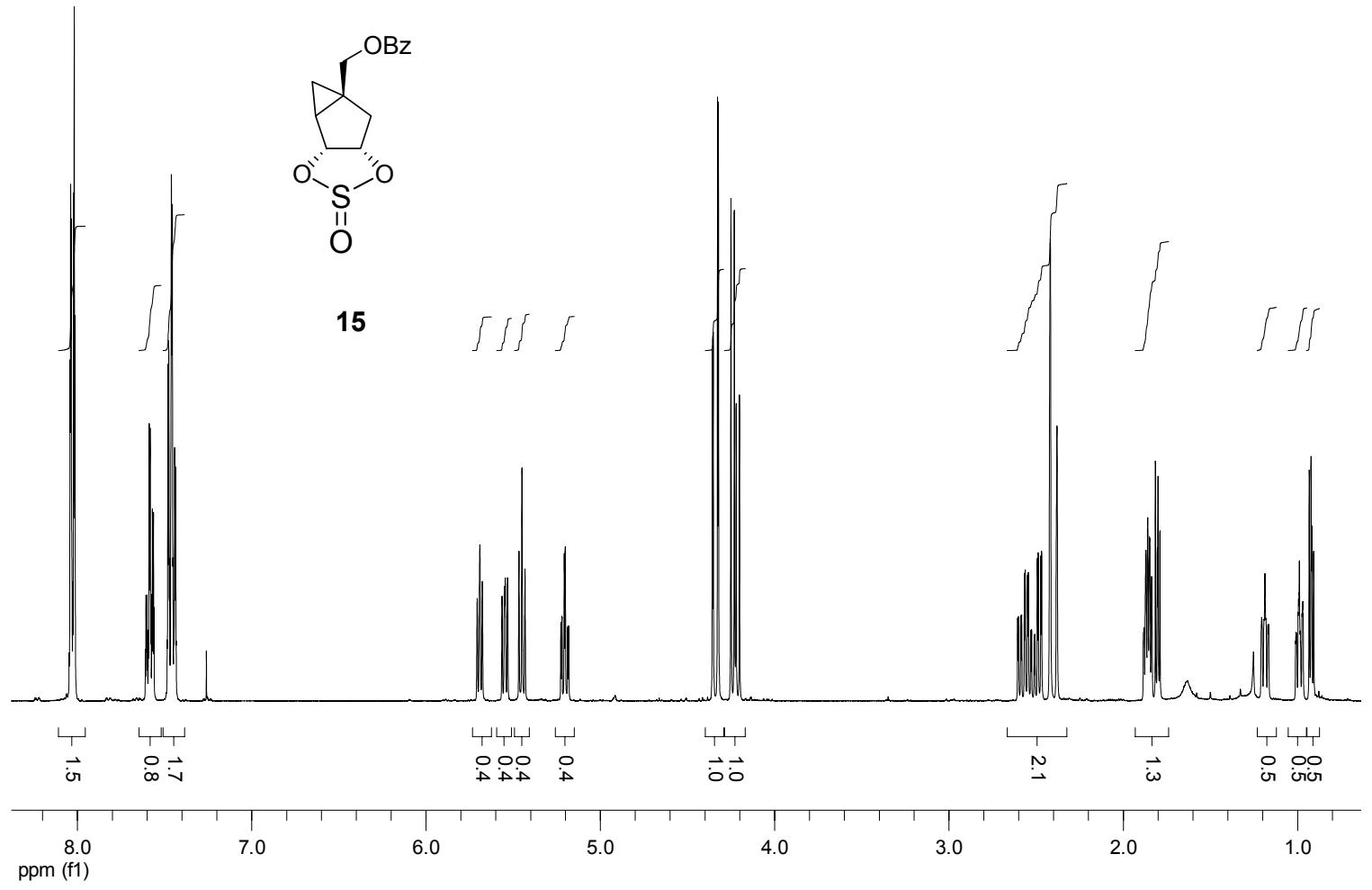




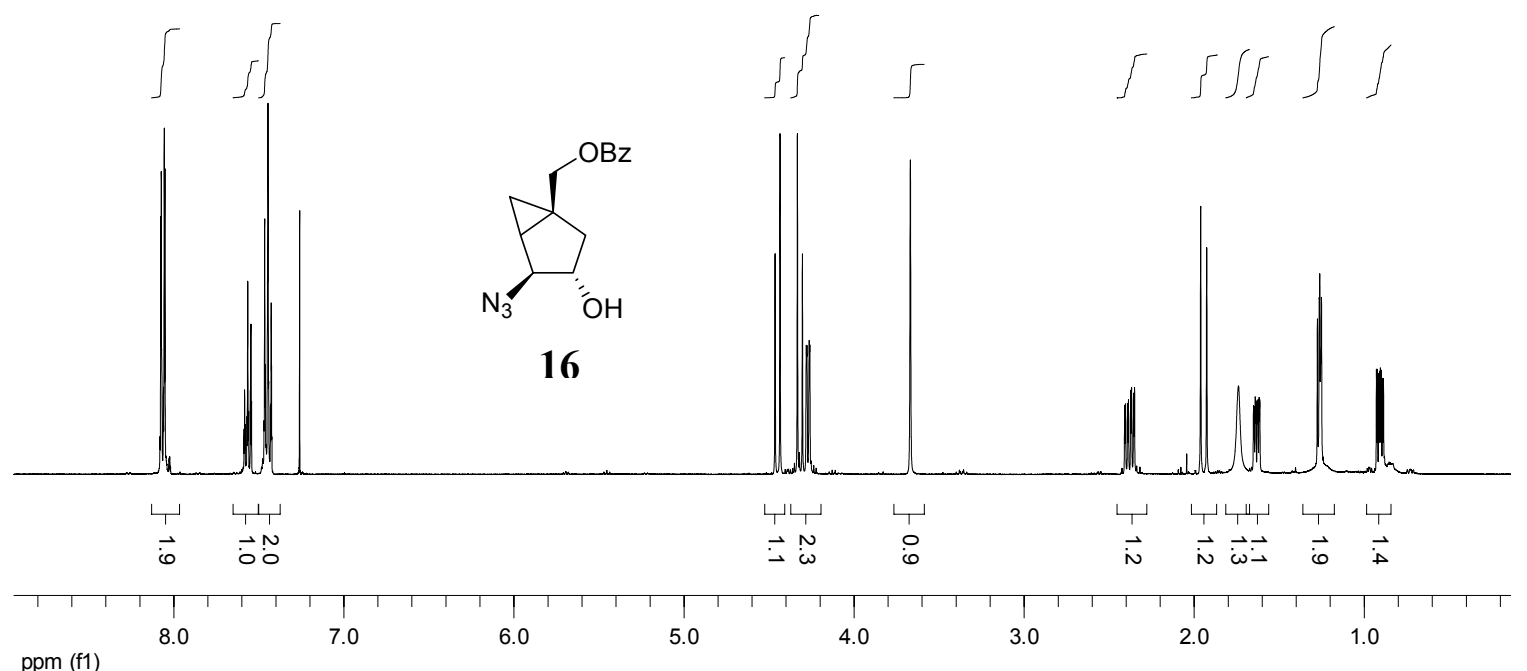

ppm (f1)

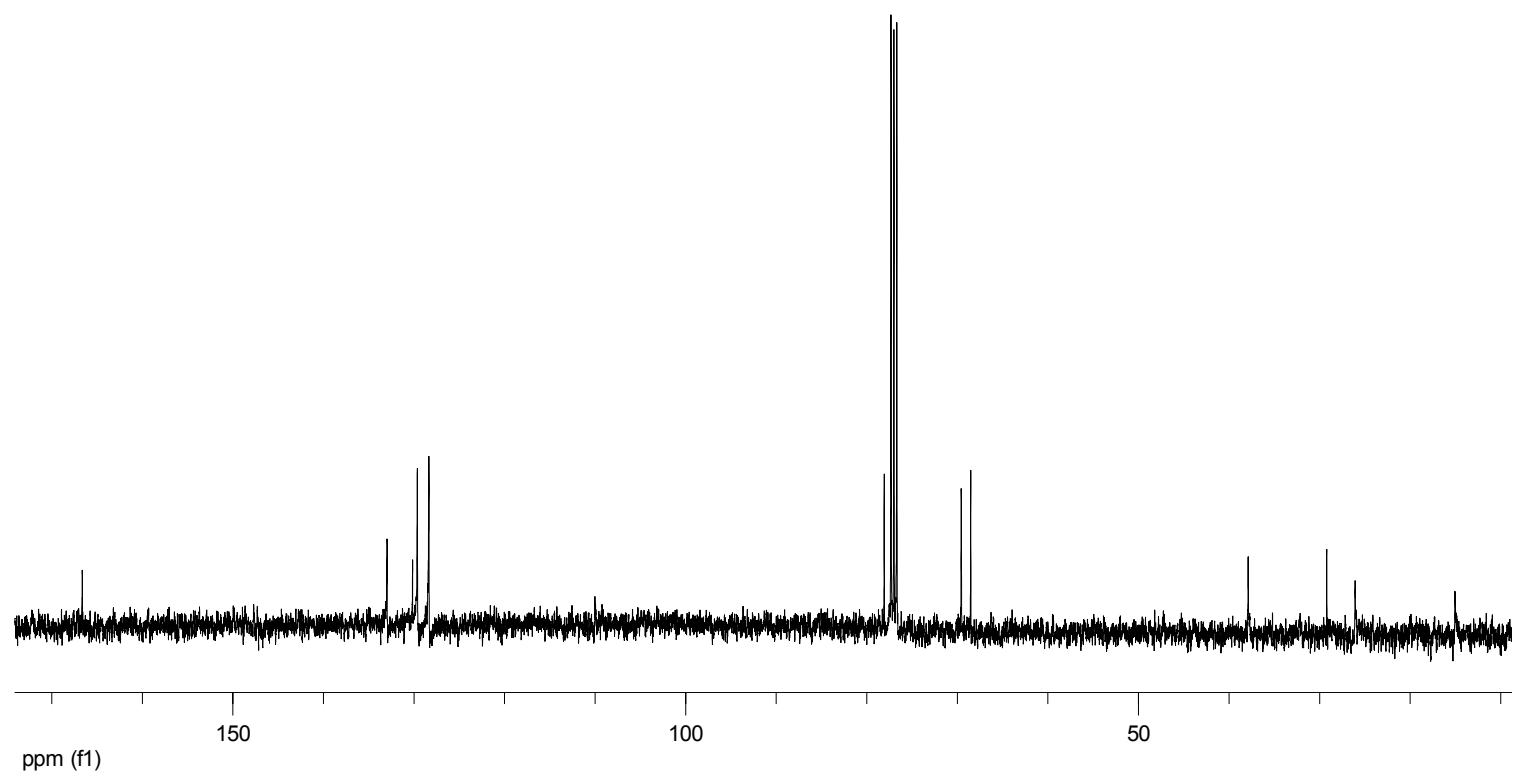

ppm (f1) 

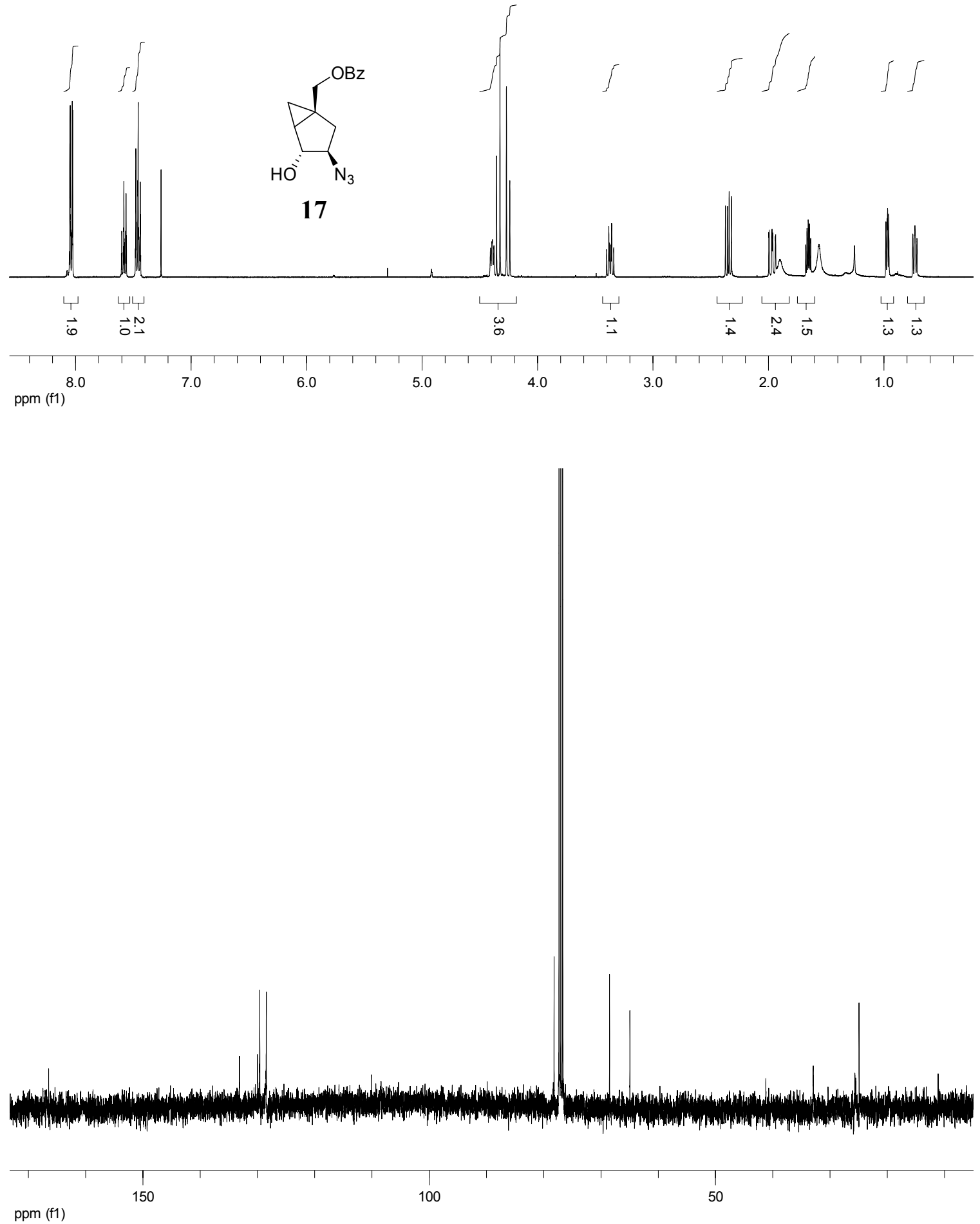

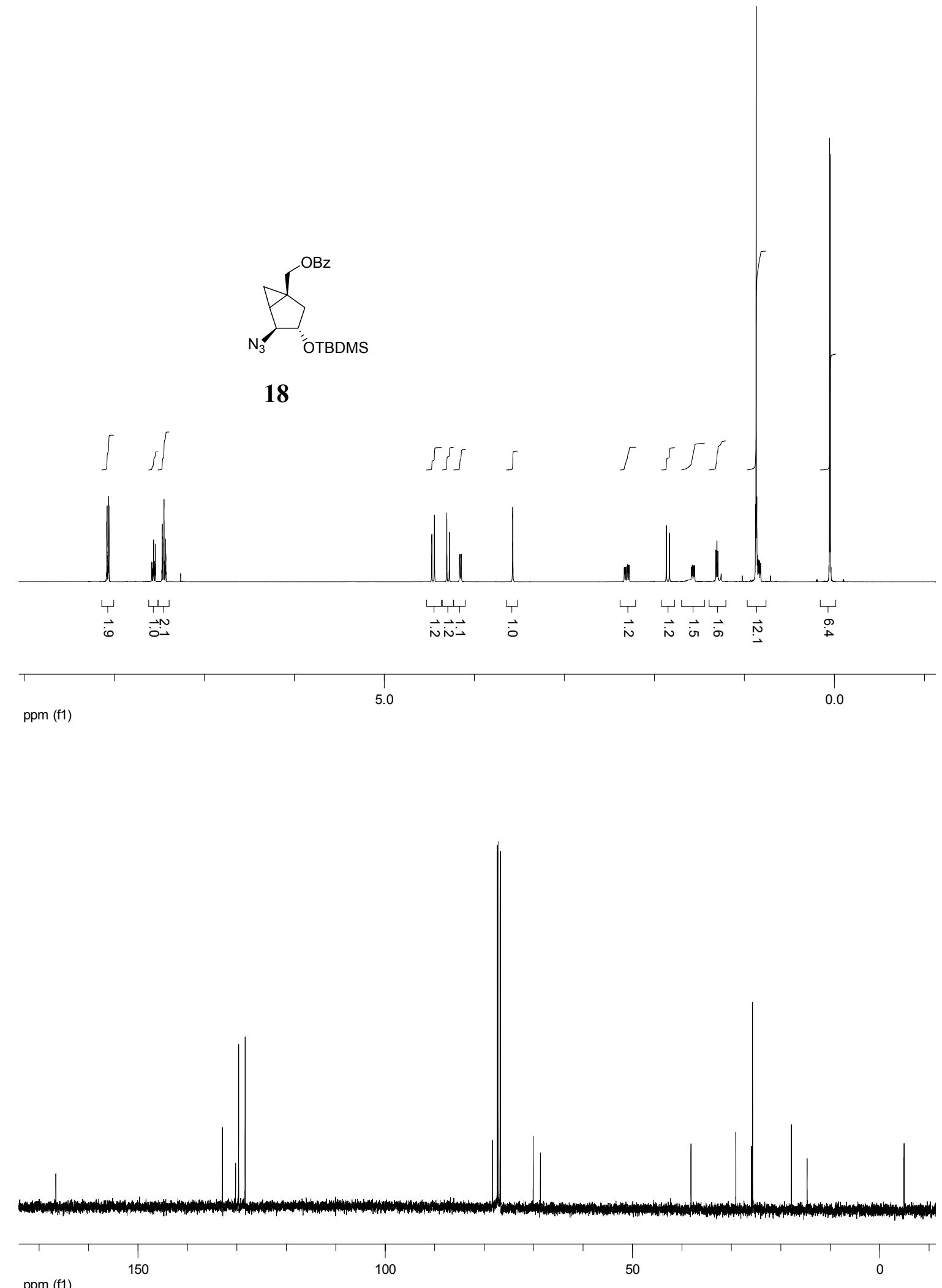


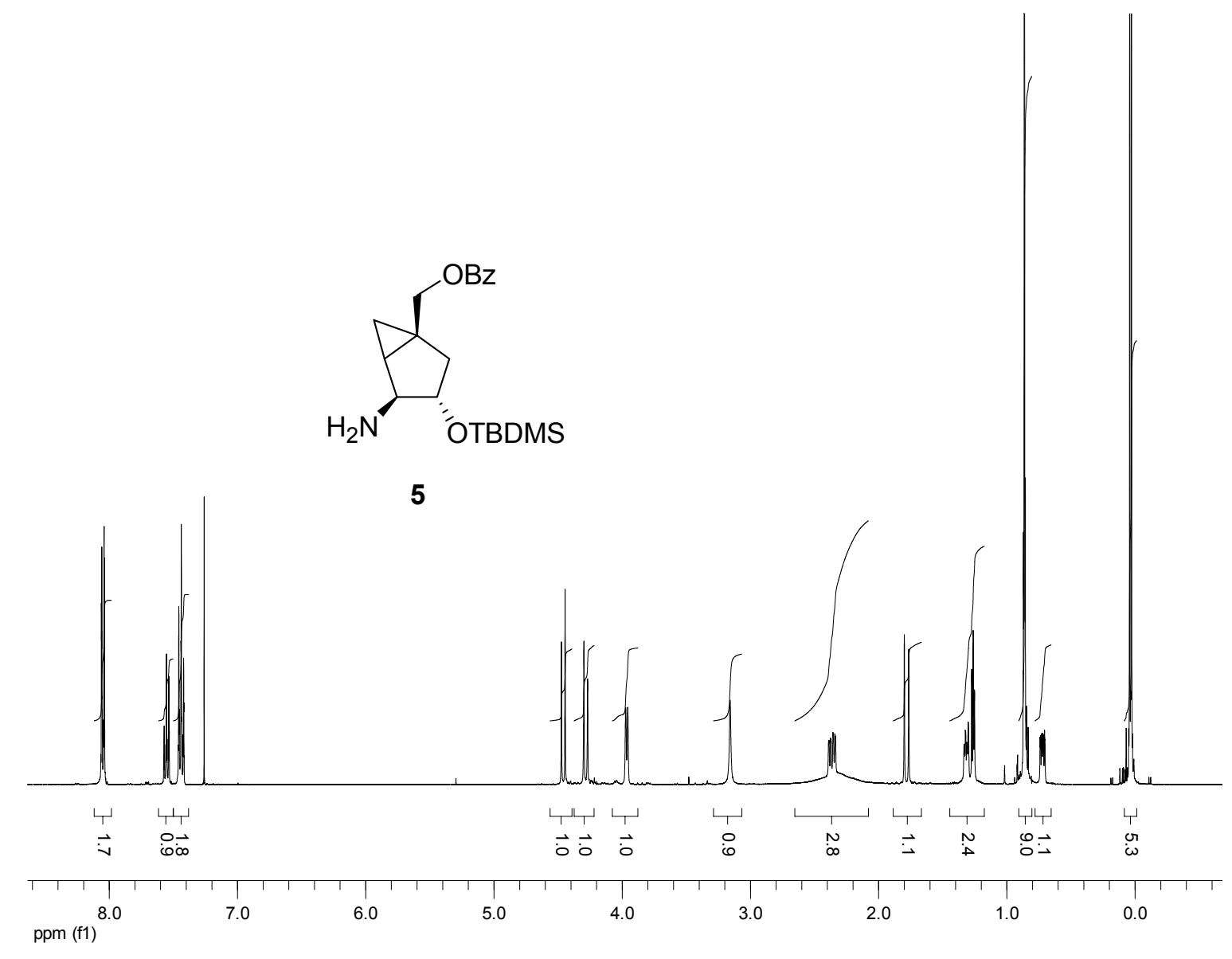



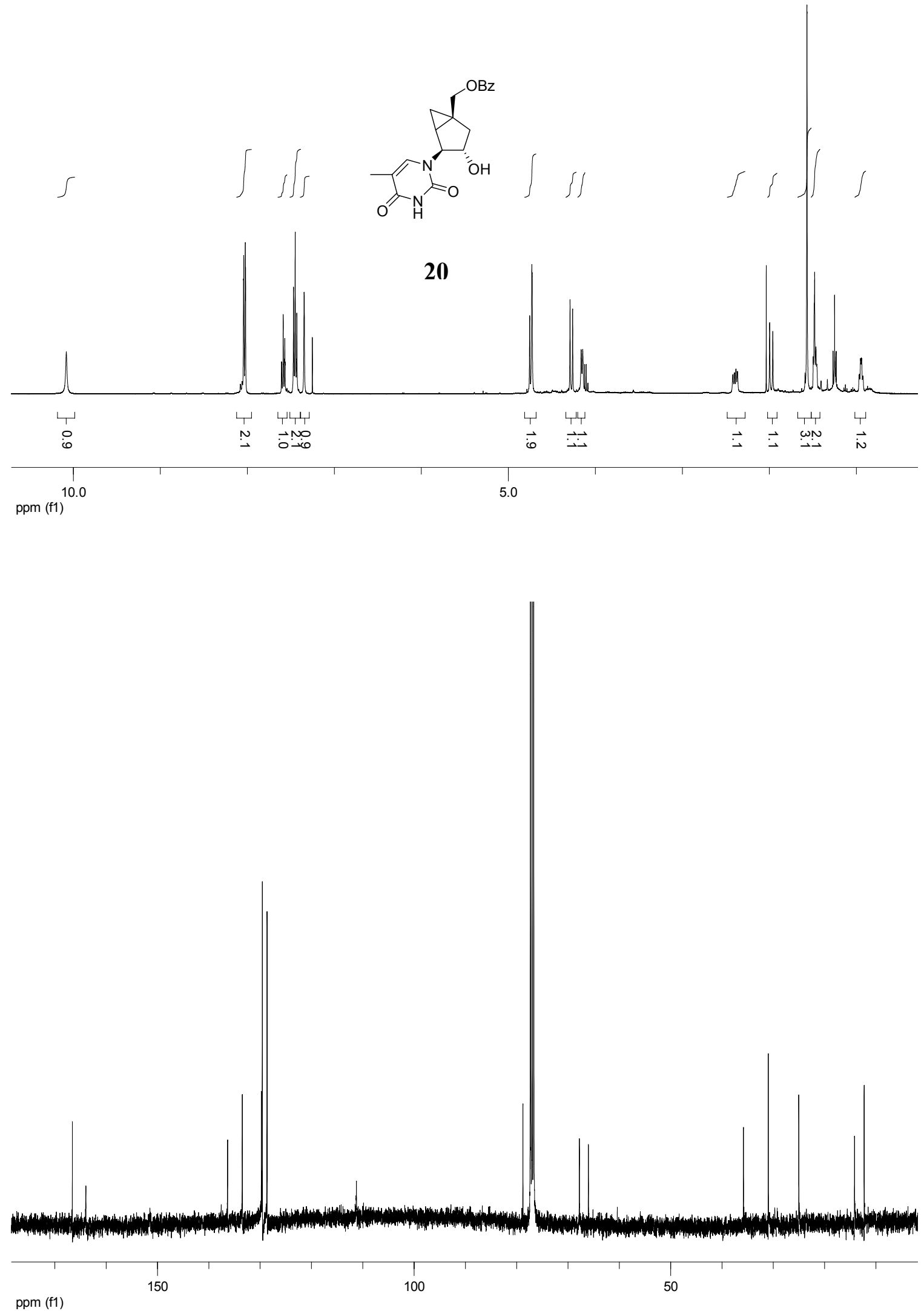

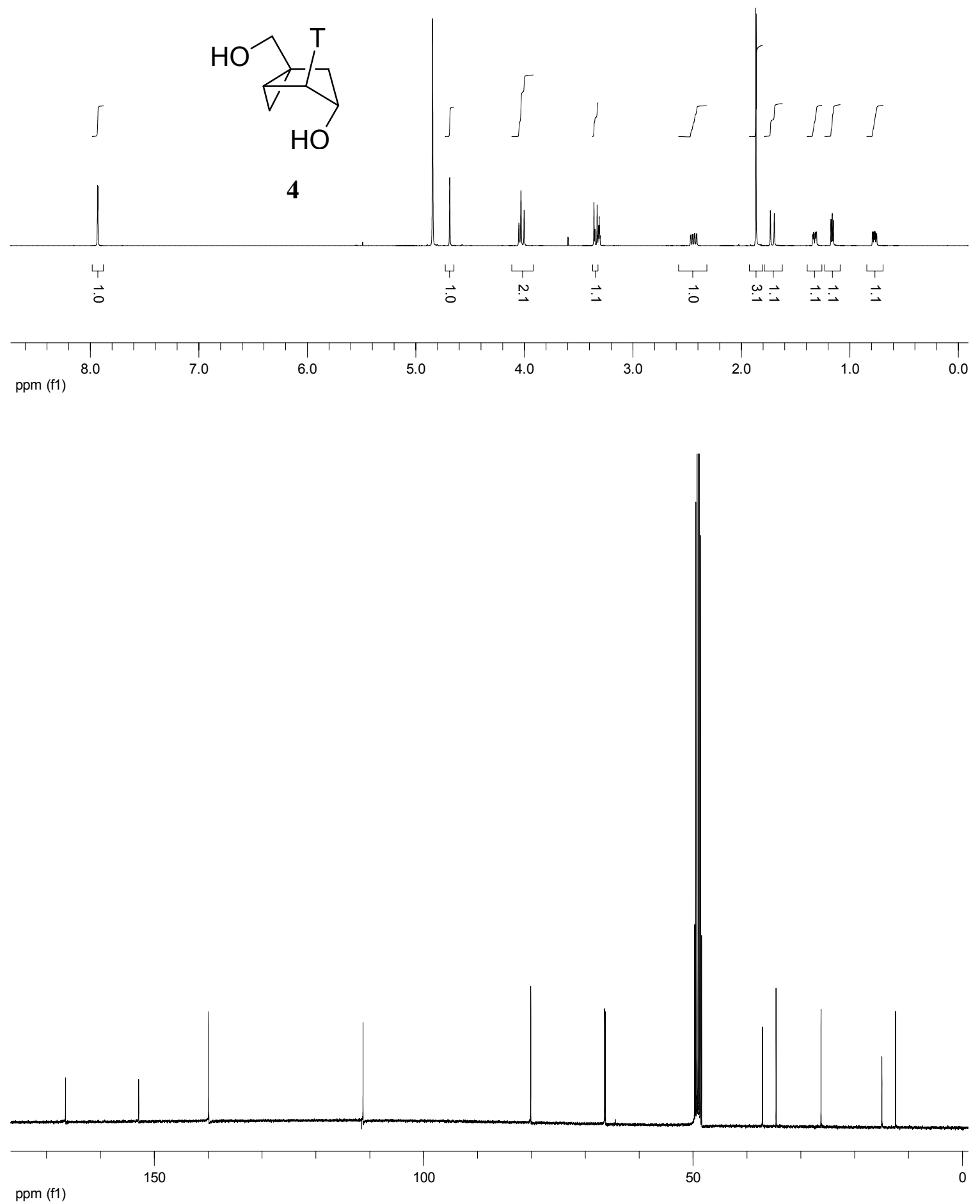